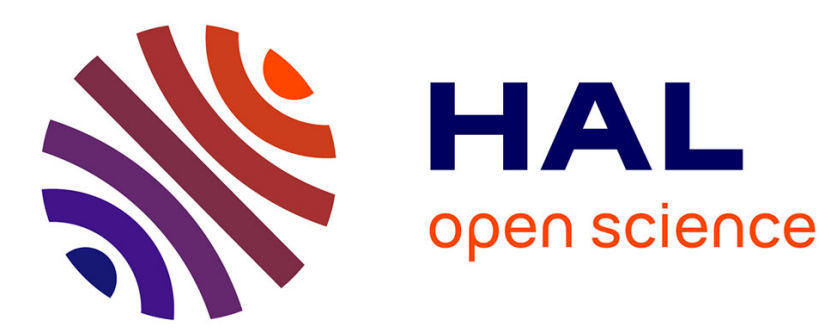

\title{
Oil slick volume estimation from combined use of airborne hyperspectral and pool experiment data
}

Laure Roupioz, Françoise Viallefont-Robinet, Véronique Miegebielle

\section{To cite this version:}

Laure Roupioz, Françoise Viallefont-Robinet, Véronique Miegebielle. Oil slick volume estimation from combined use of airborne hyperspectral and pool experiment data. IGARSS 2019, Jul 2019, YOKOHAMA, Japan. 10.1109/IGARSS.2019.8899057 · hal-02397170

\section{HAL Id: hal-02397170 \\ https://hal.science/hal-02397170}

Submitted on 6 Dec 2019

HAL is a multi-disciplinary open access archive for the deposit and dissemination of scientific research documents, whether they are published or not. The documents may come from teaching and research institutions in France or abroad, or from public or private research centers.
L'archive ouverte pluridisciplinaire HAL, est destinée au dépôt et à la diffusion de documents scientifiques de niveau recherche, publiés ou non, émanant des établissements d'enseignement et de recherche français ou étrangers, des laboratoires publics ou privés. 


\title{
OIL SLICK VOLUME ESTIMATION FROM COMBINED USE OF AIRBORNE HYPERSPECTRAL AND POOL EXPERIMENT DATA
}

\author{
Roupioz Laure ${ }^{1}$, Viallefont-Robinet Françoise ${ }^{1}$, Miegebielle Véronique ${ }^{2}$ \\ ${ }^{1}$ ONERA, 2 avenue E. Belin, BP 74025, 31055 Toulouse Cedex 4, FRANCE \\ ${ }^{2}$ TOTAL, Recherche, CSTJF, 6 Avenue Larribau, 64018 Pau, FRANCE
}

\begin{abstract}
To date, estimating oil thickness on the sea surface remains a challenge in most cases. When oil thickness estimation using optical data is limited by the absorption properties of the target, a solution consists in combining experimental and airborne hyperspectral data. We developed a method to identify thickness classes from hyperspectral data which, combined with realistic thickness values derived from a pool experiment, allows to estimate slick volume. Hyperspectral images of the same oil emulsion were acquired over a pool and at sea, under real conditions. From the pool data, we derived two classes: the sheen and the thick pixels, along with their respective thickness. These classes are then identified on the airborne images acquired during the NOFO campaign by generating a detection mask and using two classification approaches based on spectral indices. The proposed method allows to correctly identify the two thickness classes and, combined with the data from the pool experiment, provides a total slick volume larger than the one derived for the Bonn Agreement Oil Appearance Code.
\end{abstract}

Index Terms - Oil slick detection, oil thickness, pool experiment, airborne hyperspectral imagery

\section{INTRODUCTION}

Although there is a crucial need for reliable oil slick volume estimation, still few methods are available to accurately measure oil-on-water slick thickness [1]. In the framework of NAOMI (New Advanced Observation Method Integration), a research project conducted by TOTAL and ONERA, the potential of hyperspectral images to estimate oil thickness is investigated. Laboratory analyses already pointed out that, in the optical domain, it is not possible to probe a layer of oil beyond its skin depth which is directly linked to its absorption properties. For the oil-in-water emulsion products studied in our lab, the measured skin depth was found much lower than one millimeter, preventing the direct reliable estimation of their actual thickness when spilt over sea water. To overcome this issue, we developed a method to identify oil emulsion thickness classes from airborne hyperspectral data which, combined with realistic thickness values derived from a pool experiment, allows to estimate the slick volume. First, we investigated the behavior of several products in a controlled environment using hyperspectral images acquired during the CEDRE pool experiment. From it, we estimated average thickness values for two representative classes of an oil emulsion for which airborne hyperspectral images were also acquired under real conditions during the NOFO cleanup exercise. Classification maps identifying the two defined thickness classes are generated from the airborne images using the proposed method. In this method, an oil slick detection mask is created before classifying the detected slick. By combining the classification maps with the thickness information derived from the CEDRE experiment, the slick volume can be estimated. The current reference for oil slick volume estimation being the Bonn Agreement Oil Appearance Code (BAOAC), a visual color-based evaluation, the volumes estimated with the proposed method are compared with estimations based on the BAOAC.

\section{DATA COLLECTION CAMPAIGNS}

\subsection{At sea campaign: NOFO 2015}

The estimation of oil slick volume is carried out on a cloud free subset extracted from the hyperspectral images acquired during the cleanup exercise conducted by NOFO (Norwegian Clean Seas Association for Operating Companies), the $9^{\text {th }}$ June 2015 in the North Sea [2]. During this exercise, about $50 \mathrm{~m}^{3}$ of oil emulsion were spilled at sea. The data were acquired by two HySpex hyperspectral cameras operated from an airplane, in the VNIR $(0.4-1 \mu \mathrm{m})$ and in the SWIR $(1-2.5 \mu \mathrm{m})$ respectively. In this study, we only used the VNIR images which have a spatial resolution of $0.8 \times 0.8 \mathrm{~m}$. The images are registered and corrected for the effects of the atmosphere.

\subsection{Pool experiment: CEDRE 2017}

Hyperspectral images of the same oil emulsion (referred as NOFO emulsion hereafter) remixed on site, were acquired 
with the same cameras in a controlled environment for the pool experiment conducted during the CEDRE campaign in 2017. During this campaign, 13 different products were tested. The measurements were performed over still sea water with small quantities of products poured into a frame [3], the surface covered by the product remaining smaller than the surface delimited by the frame. In parallel, laboratory measurements of the transmission and reflectance of the oil emulsion were performed at ONERA [4].

\section{OIL DETECTION AND QUANTIFICATION METHOD}

\subsection{Oil regime information derived from the CEDRE experiment}

From the known volume poured into the pool and the surface covered by the product, we could compute the product average thickness for each product studied during the CEDRE campaign. Thanks to the hyperspectral data, we thoroughly analyzed each product to detect possible thickness variations within the slick. During this experiment, most of the pure products spread rather homogeneously over the water. From these observations, we derived information about the general behavior of oil on sea water and observe that, concerning oil sheen resulting from fluid and light products, our measurements showed an average thickness frequently close to $0.025 \mathrm{~mm}$.

Concerning the NOFO emulsion, differences in thickness within the slick were clearly identified as show in Fig. 1. To estimate the thickness of this product, we first divided the slick into two classes based on several indices identified in the literature as reliable to detect hydrocarbons. Among the tested indices, we selected the Fluorescence Index (FI) [4], the Rotation-Absorption Index (RAI) [4] and the Hydrocarbon Index (HI) [5]. Concerning HI, the wavelengths used for the computation were adapted to our study. The equations to compute these indices are provided in Table 1. Based on the frequency distribution histogram of these indices, we split the slick in two classes. The first class identified as "sheen" and the second as "thick pixels". Knowing the volume poured into the pool $(500 \mathrm{ml})$, considering a sheen thickness of $0.025 \mathrm{~mm}$, using $\mathrm{HI}$ and automated thresholding, we estimated the thickness of the thick pixels as $1.1 \mathrm{~mm}$.

Table 1. Indices formulas

\begin{tabular}{|l|c|}
\hline Fluorescence Index & FI $=\left(\begin{array}{c}(\rho .47-\rho 0.67) /(\rho 0.47+ \\
\rho 0.67)\end{array}\right.$ \\
\hline $\begin{array}{l}\text { Rotation-Absorption } \\
\text { Index }\end{array}$ & $\begin{array}{c}\text { RAI }=\|\rho\|(\rho 0.47-\rho 0.85) / \\
(\rho 0.47+\rho 0.85)\end{array}$ \\
\hline Hydrocarbon Index & $\begin{array}{l}\mathrm{HI}=[(1.72-1.67) /(1.75-1.67)] \\
(\rho 1.75-\rho 1.67)+\rho 1.67-\rho 1.72\end{array}$ \\
\hline
\end{tabular}
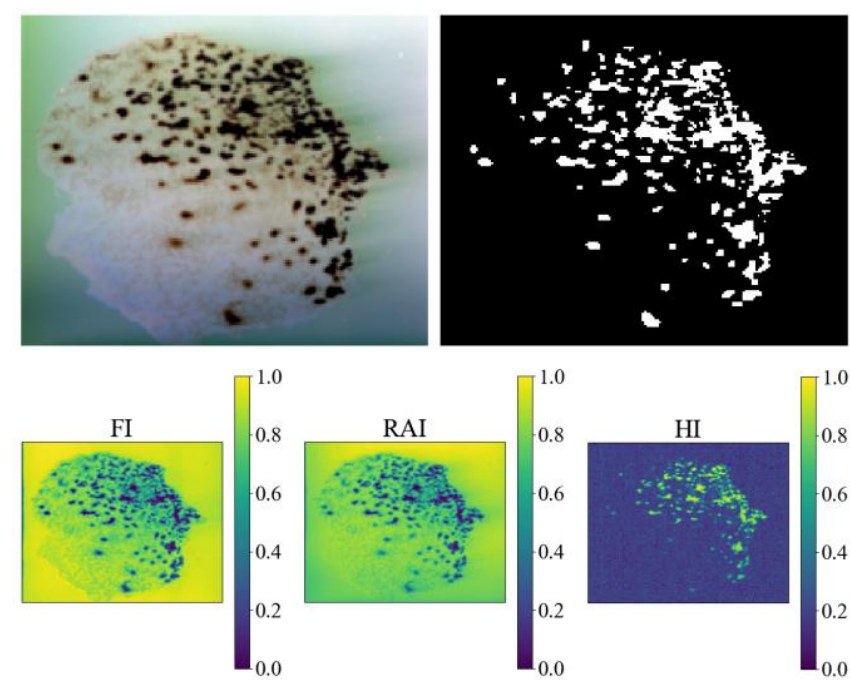

Fig. 1. NOFO emulsion analysis from data acquired during the CEDRE campaign. Top: RGB stretched display and thick pixels identification. Bottom: computed FI, RAI and HI maps linearly stretched between 0 and 1

\subsection{Thickness classification maps from the NOFO campaign airborne data}

The idea is to produce a thickness classification map providing the two thickness classes which correspond to the ones identified on the CEDRE data for the subset zone extracted from the hyperspectral images acquired during the NOFO campaign. The first step consists in detecting the oil slick and to produce a detection mask. In the proposed method, the slick detection is performed on FI values. FI being a band ratio, using this index allows to get rid off part of the artefacts inherent to data acquisition in real maritime environment. However, the sun glint can still impact the oil slick detection. Thus, prior to compute FI, a mask is created based on image spectral statistics to remove pixels with very high spectral mean values. From the FI frequency distribution histogram, the split value to separate oil contaminated and non contaminated pixels is determined based on automatic mode detection. Finally, the created detection mask is smoothed using median filtering with a window size of 9 , to fill the empty pixels masked out because of sun glint and to remove the noise generated by isolated pixels.

In a second step, the detected slick is divided into two classes: "sheen" and "thick pixels". To do so, we classified the slick based on FI and RAI. HI is not used in this case as only the VNIR images are considered. As for the creation of the detection mask, the two classes are identified based on the frequency distribution histogram of each indices and an automated mode detection. Only the parametrization of the detection is different between the two steps.

Considering that the NOFO emulsion mixing is relatively similar between the pool and the sea cases, the thicknesses 
found for the pool experiment can be used for the volume assessment in the airborne case.

\section{APPLICATION TO NOFO AIRBORNE DATA}

\subsection{Oil slick detection}

The slick detection mask generated automatically for the subset zone covers an area of $122540 \mathrm{~m}^{2}$ and is presented in Fig. 2. Visual check shows that the generated detection mask is accurate and encompasses correctly the different parts of the slick. To quantify the accuracy of this mask, a detection mask digitalized manually on the original hyperspectral image is used as reference. The comparison shows that the mask created by the proposed method covers a surface $15 \%$ smaller than the reference one. The missing parts are mostly located on the edge of the slick were there is only a very thin sheen of oil. The created mask appears also more fragmented than the reference one. Based on the sheen thickness used in this study $(0.025 \mathrm{~mm})$, the area difference between the two masks would represent $0.5 \mathrm{~m}^{3}$ of NOFO emulsion for our test zone, which represents less than $3 \%$ of the total estimated volume. When calculating this difference using the BAOAC sheen thickness, the volume differences become negligible. Furthermore, the manual delineation is also subject to the operator interpretation and can vary from one person to another. When considering slick volume estimation, this comparison confirms that the proposed automatic detection method provides satisfying results over the test zone.
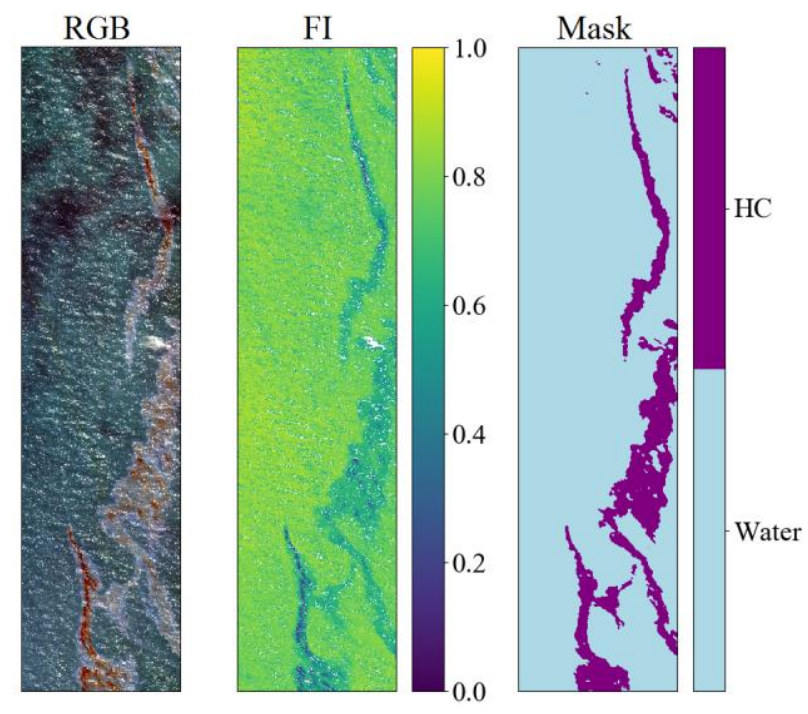

Fig 2. Detection mask generated automatically from NOFO airborne data for the subset zone. From left to right: airborne image subset, FI map and corresponding detection mask

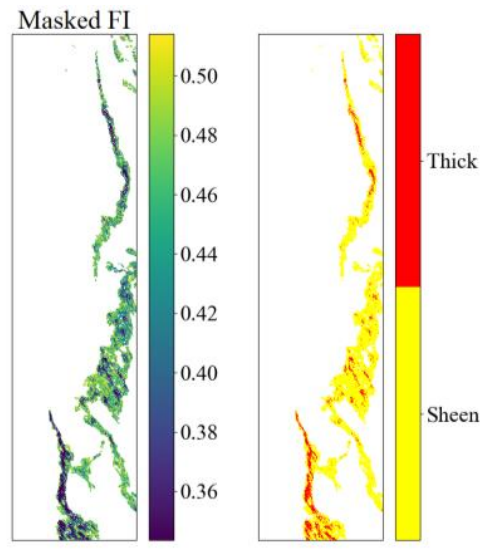

Fig. 3. Thickness classes identification from NOFO airborne data for the subset zone: FI values in the detection mask (left) and corresponding classification maps (right)

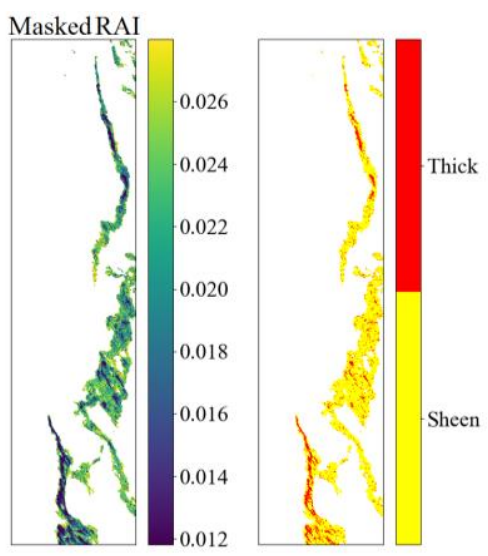

Fig. 4. Thickness classes identification from NOFO airborne data for the subset zone: RAI values in the detection mask (left) and corresponding classification maps (right)

\subsection{Oil slick volume estimation}

\subsubsection{Volume estimation based on FI}

The thickness classification map derived from FI is presented in Fig. 3 and, based on visual checks, provides satisfying identification for the two thickness classes. For the subset zone, the surface covered by the sheen is estimated as $109007 \mathrm{~m}^{2}$ and for the thick pixels as $13533 \mathrm{~m}^{2}$. Using a sheen thickness of $0.025 \mathrm{~mm}$ and a thick pixel thickness of $1.1 \mathrm{~mm}$, we obtain a total slick volume of $17.4 \mathrm{~m}^{3}$.

\subsubsection{Volume estimation based on RAI}

The thickness classification map based on RAI is presented in Fig. 4 and, as for FI, provides satisfying results. For the subset zone, the surface covered by the sheen is estimated as $105448 \mathrm{~m}^{2}$ and for the thick pixels as $17092 \mathrm{~m}^{2}$. Using a sheen thickness of $0.025 \mathrm{~mm}$ and a thick pixel thickness of $1.1 \mathrm{~mm}$, we obtain a total slick volume of $21.4 \mathrm{~m}^{3}$. 


\subsubsection{Comparison with BAOAC estimation}

Currently, the Bonn Agreement Oil Appearance Code (BAOAC) is considered as reference and remains widely used in operational context to estimate oil slick volume. It consists in a color code that relates the color to the thickness of oil on the sea. This code was build based on the literature and the theory of the effect of oil on a water surface appearance [6]. For each appearance class, it provides a minimum and a maximum thickness value from which a volume range can be computed. Concerning the thicker class, only a lower limit is provided. In this study, we visually applied this code on the NOFO airborne hyperspectral images. The appearance classes identification was performed within the reference detection mask. As mentioned earlier, the volume estimation obtained with both masks being very close, we used the reference one to simulate a real operational context. The estimated total slick volume ranges from $5.7-18.2 \mathrm{~m}^{3}$ for the subset zone. Table 2 summarizes the volume estimations obtained with the presented approach and compares them with the results derived from the BAOAC. This comparison shows that the volume range estimated using the $\mathrm{BAOAC}$ is relatively large and that the provided values are, in average, significantly lower than the ones obtained with the proposed method. This is mostly explained by the large difference between the upper thickness limit of the BAOAC $(0.2 \mathrm{~mm})$ and the one observed during the pool experiment and used in this study $(1.1 \mathrm{~mm})$. The BAOAC is a tool created to provide an estimation of the minimum oil volume that could be contained in a slick. The approach proposed in this study aims at introducing more realistic thickness values to obtain total slick volume estimation closer from the reality.

Table 2. Slick volume estimation comparisons

\begin{tabular}{|l|c|}
\hline $\begin{array}{l}\text { Volume estimation } \\
\text { based on }\end{array}$ & $\begin{array}{c}\text { Volume } \\
\left(\mathrm{m}^{3}\right)\end{array}$ \\
\hline FI & 17.4 \\
\hline RAI & 21.4 \\
\hline BAOAC (min - max) & $5.7-18.2$ \\
\hline
\end{tabular}

\section{CONCLUSIONS}

The results show that the proposed method allows to accurately detect the oil slick and to correctly differentiate the sheen and the thick pixels within the slick. The method performed well over the test zone. It would now be interesting to develop this method in order to detect more classes and to identify automatically the classes from the Bonn Agreement Oil Appearance Code. The indices used to identify the thickness classes, FI and RAI, provide satisfying results even if RAI tends to detect more thick pixels than FI. Those indices can also be computed using lower spectral resolution images such as multispectral satellite data. When using satellite data, other issues such as mixed pixels may occur, and the following step would be to apply and, if necessary, adapt this method to this type of data.

Concerning the slick volume estimation, its accuracy strongly relies on the similarity of the mixing of the emulsion between sea and pool experiment and the relation between the thickness estimated during the pool experiment and the behavior of the oil on sea water, under real conditions. In this study, we use the thickness measured in a controlled environment and on still water. It is certain that the impact of the waves, the current, the water salinity and temperature will affect the spreading the oil emulsion on the water surface and that the true thickness may differ from the one observed in the pool. However, by analyzing and integrating oil regime information in our estimations, we get closer from a realistic slick volume than with the current method used in operational context. It is then essential to further analyze and understand oil regime on the water surface to provide more reliable estimations.

\section{Acknowledgments}

This work was carried out in the framework of the NAOMI research project a partnership between TOTAL and ONERA. We would like to thank the NOFO, the CEDRE and all the persons, including ONERA \& TOTAL colleagues, involved in the two experiments.

\section{REFERENCES}

[1] M. Fingas, "The challenges of remotely measuring oil slick thickness", Remote Sensing, 10(2), pp. 319, 2018.

[2] S. Angelliaume, X. Ceamanos, F. Viallefont-Robinet, R. Baqué, P. Déliot, V. Miegebielle, "Hyperspectral and Radar Airborne Imagery over Controlled Release of Oil at Sea", Sensors, 17(8), pp. 1772, 2017.

[3] F. Viallefont-Robinet, A. Moussous, P. Déliot, L. Roupioz, V. Miegebielle, "Analysis of water-in-oil emulsion hyperspectral signature: contribution of pool experiment", SPIE Remote Sensing, 2018.

[4] M. Lennon, V. Mariette, A. Coat, V. Verbeque, P. Mouge, G.A. Borstad, P. Willis, R. Kerr, M. Alvarez, "Detection and mapping of the November 2002 Prestige tanker oil spill in Galicia, Spain, with the airborne multispectral CASI sensor", 3rd EARSEL workshop on Imaging Spectroscopy, 2003.

[5] F. Kühn, K. Oppermann, B. Hoerig, "Hydrocarbon Index-An algorithm for hyperspectral detection of hydrocarbons", International of Remote Sensing, 25, pp. 2467-2473, 2004.

[6] Bonn Agreement, "Guidelines for Oil Pollution Detection: Investigation and Post Flight Analysis/Evaluation for Volume Estimation", 2017. Available online: www.bonnagreement.org (accessed on 4 January 2019). 